\title{
Validação de escala de desenvolvimento para cultivares brasileiras de arroz irrigado
}

\author{
Validation of the development scale for Brazilian flooded rice cultivars
}

\author{
Thais Fernanda Stella de Freitas ${ }^{1}$ Paulo Regis Ferreira da Silva ${ }^{{ }^{*}}$ \\ Mércio Luiz Strieder ${ }^{1}$ Adriano Alves da Silva ${ }^{1}$
}

\section{RESUMO}

A falta de adoção de uma escala de desenvolvimento apropriada para a cultura do arroz irrigado leva à utilização do número de dias após a emergência, que varia muito com a cultivar e com as condições edafoclimáticas, ao invés de se basear em estádios fenológicos para referir-se a um estádio da planta. O objetivo desta pesquisa foi validar o uso da escala de desenvolvimento para três cultivares brasileiras de arroz irrigado, de ciclos distintos, em três épocas de semeadura. O experimento foi conduzido em tanques em Porto Alegre, RS. Os tratamentos constaram de três épocas de semeadura (14 de outubro, 13 de novembro e 18 de dezembro de 2003) e de três cultivares de arroz irrigado (BR-IRGA 409, ciclo médio; IRGA 417, ciclo precoce, e IRGA 421, ciclo superprecoce). Foram semeadas três linhas de cada cultivar por tanque, espaçadas em $0,15 \mathrm{~m}$, com a população de 250 plantas $\mathrm{m}^{-2}$. Dez plantas foram identificadas e avaliadas na linha intermediária de cada cultivar. Em todas as cultivares $e$ épocas de semeadura, as plantas atingiram o estádio $R 1$ (diferenciação do primórdio da panícula) com sete folhas expandidas, correspondendo a diferentes idades cronológicas. Com atraso da época de semeadura, somente a cultivar superprecoce reduziu o número de folhas expandidas ao atingir o estádio de formação do colar na folha bandeira (R2). No entanto, o número de dias após a emergência para atingir este estádio variou entre cultivares. O número de dias necessários para atingir cada estádio de desenvolvimento e o ciclo total das cultivares diminuiram à medida que se atrasou a época de semeadura. $O$ sub-período em que se registrou maior variação no número de dias foi do estádio $R 1$ a $R 2$, independente de cultivar ou época de semeadura. A escala proposta foi eficaz para descrever o desenvolvimento da planta de três cultivares brasileiras de arroz irrigado. Assim, propicia a realização de intervenções de manejo na época correta, que é um dos fatores determinantes da obtenção de elevados rendimentos de grãos $e$ do uso racional dos insumos.
Palavras-chave: Oryza sativa, época de semeadura, fenologia, ciclo de desenvolvimento.

\begin{abstract}
The number of days after emergency is commonly used to define the rice plant stage, despite the existence of a growth scale. The use of chronological time is not ideal, once it is dependent of the cultivar life cycle and environmental conditions, which are known to affect the plant development. The goal of this study was to validate a rice growth scale for three Brazilian flooded rice cultivars, with different life cycles and in three sowing dates. The experiment was conducted in tanks in Porto Alegre, RS, Brazil. The three sowing dates were October 14, November 13 and December 18, 2003, and the cultivars chosen were BR-IRGA 409, medium cycle, IRGA 417, early cycle, and IRGA 421, very early cycle. Each cultivar was sowed in three lines, spaced $0.15 \mathrm{~m}$ from each other, to produce a population of 250 plants $\mathrm{m}^{-2}$. Ten plants composed each sample. The R1 stage (panicle differentiation) was reached when the plants had seven expanded leaves in all treatments, independently of the chronological plant age. A reduction in the number of expanded leaves at the R2 stage (flag leaf collar formation) was only observed for IRGA 421 in the last sowing date. However, the number of days required for each cultivar to reach $R 2$ stage was different. As the sowing date was delayed, the chronological time between each growth stage was reduced. The rice growth scale was much more efficient than the chronological age to determine the plant stage. Therefore, using the rice growth scale is possible to interfere at the correct moment, allowing high yields and rational resource use.
\end{abstract}

Key words: Oryza sativa, sowing dates, phenology, development cycle.

\footnotetext{
${ }^{1}$ Programa de Pós-graduação em Fitotecnia da Universidade Federal do Rio Grande do Sul (UFRGS), Faculdade de Agronomia, Departamento de Plantas de Lavoura, Av. Bento Gonçalves, 7712, 91501-970, Porto Alegre, RS, Brasil. E-mail: paulo.silva@ufrgs.br. Autor para correspondência*.
} 


\section{INTRODUÇÃO}

A eficiência de uma tecnologia agrícola depende de sua aplicação correta em relação à técnica adotada e ao momento oportuno de aplicação (COSTA \& MARCHEZAN, 1982). A decisão da época correta de adoção é fundamental para obtenção de maior resultado econômico e de menor impacto ambiental negativo. Para tanto, faz-se necessário um meio de comunicação comum a todos os segmentos envolvidos na cadeia produtiva de uma determinada cultura.

Para a maioria das espécies cultivadas, já existem escalas de desenvolvimento que universalizam a linguagem entre pesquisadores, extensionistas e produtores, de forma simples e de fácil compreensão. Na cultura do milho, é adotada a escala proposta por RITCHIE et al. (1993), na qual o desenvolvimento da planta é dividido em estádios vegetativos, conforme o número de folhas expandidas, e reprodutivos, conforme o estádio de maturidade dos grãos. Para o trigo, MUNDSTOCK (1999) cita a utilização de escalas que caracterizam os estádios de desenvolvimento da planta com maior ou menor detalhamento, utilizadas conforme os objetivos do trabalho: $1^{\text {a }}$ ) a escala proposta por Feekes em 1941 e ilustrada e ampliada por Large em 1954; 2aㅗ ) escala Zadocks, Chang e Konzak proposta em 1974; e $3^{\text {a }}$ ) escala de Haun, proposta em 1973. COSTA \& MARCHEZAN (1982) adaptaram a metodologia de identificação dos estádios de desenvolvimento da soja descrita por FEHR \& CAVINESS (1977) para as variedades cultivadas no Estado do Rio Grande de Sul. $\mathrm{Na}$ metodologia proposta por COSTA \& MARCHEZAN (1982), a definição dos estádios requer apenas a identificação e a contagem do número de nós do caule, constituindo uma forma simples e muito prática de utilização da escala, especialmente para produtores. Recentemente, o Instituto Agronômico do Paraná desenvolveu uma escala que caracteriza o desenvolvimento do algodoeiro herbáceo, dividindo seu ciclo em quatro fases: vegetativa, formação de botões florais, floração e capulho (MARUR \& RUANO, 2004).

Na cultura do arroz, o desenvolvimento da planta é geralmente expresso pela idade cronológica, ou seja, em número de dias após emergência, e não pela idade fisiológica. É comum, também, o uso de expressões como emborrachamento, que não representa um momento exato no desenvolvimento da planta, mas um processo que ocorre durante um período variável de dias após sua emergência, dando margem a erros de interpretação e que não representam um evento específico no seu desenvolvimento. Isto tem sido observado inclusive nas recomendações técnicas para esta cultura anteriores à disponibilizada em 2003 (SOSBAI, 2003). O número de dias após a emergência pode variar muito em função de ciclo de cultivar, temperaturas do solo, do ar e da água de irrigação, disponibilidade de radiação solar, condições hídricas e nutricionais, época de semeadura, região de cultivo e estação de crescimento. As diferenças observadas com o uso da idade cronológica das plantas podem comprometer a tomada de decisão da época de aplicação de determinada prática agrícola, pois a maioria das intervenções, como a suplementação nitrogenada em cobertura, é mais eficiente quando realizada no momento exato. Somente na última edição das indicações técnicas (SOSBAI, 2003) o uso de uma escala de desenvolvimento foi incorporado no texto.

Diante disto, fica clara a necessidade de adoção de uma escala de desenvolvimento apropriada para a cultura do arroz irrigado, que caracterize com precisão os eventos morfológicos e que utilize critérios facilmente visíveis. Para a cultura do arroz, existem algumas escalas de desenvolvimento que levam em consideração a diferenciação de folhas novas, como o filocrono, que mede o tempo entre o surgimento de uma folha e a subsequente. $\mathrm{O}$ inconveniente desta forma de avaliação é a necessidade de uso de microscópio, dificultando a análise no local de coleta do material. Para superar este tipo de dificuldade, COUNCE et al. (2000), em estudo utilizando cultivares americanas, propuseram uma escala que divide as etapas de desenvolvimento do arroz em três fases: desenvolvimento da plântula, vegetativa e reprodutiva. É importante que se teste a adaptação desta escala às cultivares brasileiras com ciclos distintos e em diferentes épocas de semeadura. Alguns dos estádios propostos podem ocorrer simultaneamente, permitindo que esta escala seja expandida ou modificada pela inclusão de mais critérios que facilitem a determinação da idade fisiológica da planta. Desta forma, a avaliação e a validação do uso desta escala de desenvolvimento para a cultura do arroz irrigado significarão um elo para melhorar a sincronia da época de aplicação de uma determinada prática de manejo entre os pesquisadores de instituições de pesquisa e os produtores no processo de transferência de informações. 
O objetivo desta pesquisa foi validar o uso da escala de desenvolvimento proposta por COUNCE et al. (2000) para três cultivares brasileiras de arroz irrigado, com ciclos distintos, em três épocas de semeadura.

\section{MATERIAL E MÉTODOS}

O experimento foi conduzido na área experimental do Departamento de Plantas de Lavoura, junto à Faculdade de Agronomia da Universidade Federal do Rio Grande do Sul, em Porto Alegre, localizada a $30^{\circ} 02^{\prime} 15^{\prime \prime}$ de latitude sul e a $51^{\circ} 13^{\prime} 13^{\prime \prime}$ de longitude oeste, região ecoclimática da Depressão Central do estado do Rio Grande do Sul, na estação de crescimento 2003/2004. O clima da região é classificado por Köppen como subtropical úmido, situado na transição entre os tipos fundamentais $\mathrm{cfa}_{1}$ (isoterma anual inferior a $18^{\circ} \mathrm{C}$ e $\mathrm{cfa}_{2}$ (isoterma anual superior a $18^{\circ} \mathrm{C}$ ). O experimento foi conduzido sob condições naturais de precipitação pluvial.

Os tratamentos constaram de três épocas de semeadura (14 de outubro, 13 de novembro e 18 de dezembro de 2003) e de três cultivares de arroz irrigado (BR-IRGA 409, ciclo médio; IRGA 417, ciclo precoce; e IRGA 421, ciclo superprecoce). As épocas adotadas correspondem às semeaduras do arroz no Estado do Rio Grande do Sul nas épocas precoce, preferencial e tardia, respectivamente. O sistema de estabelecimento da cultura foi o convencional, com a semeadura realizada manualmente, em solo seco e previamente destorroado.

Utilizaram-se tanques com dimensões de $1,30 \times 1,20 \times 0,53 m$, preenchidos com solo corrigido segundo as indicações técnicas da pesquisa para o Sul do Brasil (SOSBAI, 2003), aplicando-se 300 kgha-1 da fórmula 5-30-15 por ocasião da semeadura do arroz. A adubação nitrogenada em cobertura constou da aplicação de $70 \mathrm{~kg} \mathrm{ha}^{-1}$ de nitrogênio (N) no estádio V3, antes da entrada da água de irrigação, e de $35 \mathrm{~kg} \mathrm{ha}^{-1} \mathrm{de}$ $\mathrm{N}$ no estádio R0 da escala proposta, descrita na tabela 1. A fonte de N utilizada foi uréia (46\% de N).

Para cada cultivar foram semeadas três linhas, totalizando nove linhas por tanque, com espaçamento de $0,15 \mathrm{~m}$ e densidade inicial de 250 plantas $\mathrm{m}^{-2}$. A irrigação teve início logo após a primeira adubação nitrogenada em cobertura, quando as plantas estavam no estádio V4. A manutenção da lâmina de água em $0,10 \mathrm{~m}$ foi obtida através da instalação de bóias
Tabela 1

\begin{tabular}{|c|c|}
\hline \multicolumn{2}{|c|}{ Estádios de desenvolvimento de plântula } \\
\hline S0 - & Semente seca de arroz \\
\hline $\mathrm{S} 1-$ & Emergência do coleóptilo ou radícula \\
\hline $\mathrm{S} 2-$ & Emergência do coleóptilo e radícula \\
\hline S3 - & Emergência do profilo do coleóptilo \\
\hline \multicolumn{2}{|c|}{ Estádios de desenvolvimento vegetativo } \\
\hline $\mathrm{V} 1-$ & $\begin{array}{l}\text { Colar formado na } 1^{\text {a }} \text { folha do colmo } \\
\text { principal }\end{array}$ \\
\hline V2 & $\begin{array}{l}\text { - Colar formado na } 2^{\mathrm{a}} \text { folha do colmo } \\
\text { principal }\end{array}$ \\
\hline $\mathrm{V} 3-$ & $\begin{array}{l}\text { Colar formado na } 3^{\text {a }} \text { folha do colmo } \\
\text { principal }\end{array}$ \\
\hline V4 & $\begin{array}{l}\text { - Colar formado na } 4^{\text {a }} \text { folha do colmo } \\
\text { principal }\end{array}$ \\
\hline $\mathrm{V} 5-$ & $\begin{array}{l}\text { Colar formado na } 5^{\text {a }} \text { folha do colmo } \\
\text { principal }\end{array}$ \\
\hline V6- & $\begin{array}{l}\text { Colar formado na } 6^{\text {a }} \text { folha do colmo } \\
\text { principal }\end{array}$ \\
\hline V7 & $\begin{array}{l}\text { - Colar formado na } 7^{\text {a }} \text { folha do colmo } \\
\text { principal }\end{array}$ \\
\hline V8 - & $\begin{array}{l}\text { Colar formado na } 8^{\text {a }} \text { folha do colmo } \\
\text { principal }\end{array}$ \\
\hline V9 (VF-4) -. & $\begin{array}{l}\text { Colar formado na } 9^{\text {a }} \text { folha do colmo } \\
\text { principal, faltando } 4 \text { folhas para o } \\
\text { surgimento da folha bandeira }\end{array}$ \\
\hline V10 - (VF-3) - & $\begin{array}{l}\text { Colar formado na } 10^{\mathrm{a}} \text { folha do colmo } \\
\text { principal, faltando } 3 \text { folhas para o } \\
\text { surgimento da folha bandeira. }\end{array}$ \\
\hline V11 - (VF-2) - & $\begin{array}{l}\text { Colar formado na } 11^{\text {a }} \text { folha do colmo } \\
\text { principal, faltando } 2 \text { folhas para o } \\
\text { surgimento da folha bandeira. }\end{array}$ \\
\hline V12 - (VF-1) - & $\begin{array}{l}\text { Colar formado na } 12^{\mathrm{a}} \text { folha do colmo } \\
\text { principal, faltando } 1 \text { folha para o } \\
\text { surgimento da folha bandeira. }\end{array}$ \\
\hline $\mathrm{V} 13-(\mathrm{VF})-$ & Colar formado na folha bandeira. \\
\hline \multicolumn{2}{|c|}{ Estádios de desenvolvimento reprodutivo } \\
\hline $\mathrm{R} 0-$ & Iniciação da panícula \\
\hline $\mathrm{R} 1-$ & Diferenciação da panícula \\
\hline $\mathrm{R} 2-$ & Formação do colar na folha bandeira \\
\hline R3 - & Exserção da panícula \\
\hline R4 - & Antese \\
\hline $\mathrm{R} 5-$ & Elongação do grão \\
\hline R6 - & Expansão do grão \\
\hline R7 - & Maturidade de um grão da panícula \\
\hline $\mathrm{R} 8-$ & Maturidade completa da panícula \\
\hline
\end{tabular}

individuais nos tanques. Os manejos de pragas, moléstias e de plantas daninhas foram realizados segundo recomendações técnicas da pesquisa para o Sul do Brasil (SOSBAI, 2003).

A avaliação dos estádios de desenvolvimento da cultura foi efetuada seguindo a 
escala proposta por COUNCE et al. (2000), descrita na tabela 1. Dez plantas em seqüência foram identificadas na linha intermediária de cada tratamento. Tais plantas tiveram o desenvolvimento acompanhado durante todo o ciclo, através de duas avaliações semanais. Na fase de desenvolvimento de plântula, foi observada seqüência de emergência da radícula, do coleóptilo e do profilo. Nos estádios vegetativos, foi utilizado um fio plástico para acompanhar a emissão de folhas no colmo principal; quando uma folha apresentava o colar formado, ou seja, estava expandida conforme o critério da escala proposta, o fio plástico era transferido para esta. Nos estádios reprodutivos, as plantas eram observadas e o estádio definido quando os critérios exigidos pela escala eram identificados.

\section{RESULTADOS E DISCUSSÃO}

Na época de semeadura precoce, a duração do intervalo entre semeadura e emergência foi de nove dias, enquanto nas épocas recomendada e na tardia este intervalo diminuiu para sete dias como ilustra a figura 1. Esta variação é decorrente da menor temperatura do solo na semeadura precoce. Em trabalho conduzido para avaliar a tolerância ao frio em arroz irrigado, CRUZ (2001) verificou que a faixa ótima de temperatura do ar para germinação da semente fica entre 20 e $35^{\circ} \mathrm{C}$ e que temperaturas abaixo de $15^{\circ} \mathrm{C}$, apesar de não impedirem a germinação, retardam seu início e, conseqüentemente, a emergência das plântulas. Da mesma forma, o intervalo entre a emergência e o estádio V4, importante para aplicação de práticas de manejo como adição de $\mathrm{N}$ em cobertura, variou de 18 a 15 dias, respectivamente, nas épocas de semeadura precoce e tardia (Figura 1). Essa diferença de três dias pode corresponder a um estádio mais avançado nas semeaduras nas épocas recomendada ou tardia, podendo reduzir a eficiência de alguma prática de manejo, caso seja adotado o critério usual de número de dias após emergência.

Para a duração do sub-período emergência e diferenciação do primórdio da panícula (R1) as diferenças encontradas foram maiores. Nas épocas de semeadura precoce e preferencial este intervalo foi de 33 e 34 dias e, na época tardia, foi de apenas 25 a 27 dias, na média das três cultivares. Esta diferença de até nove dias entre as épocas de semeadura pode ser refletida na eficiência da segunda época de aplicação de $\mathrm{N}$ em cobertura, quando for adotada a idade cronológica ao invés da idade fisiológica da planta.
Com o atraso da época de semeadura, as três cultivares reduziram o número de dias após a emergência para atingir o estádio de diferenciação do primórdio da panícula (R1) (Tabela 2). No entanto, o número de folhas expandidas presentes na planta neste estádio foi o mesmo, independente de cultivar e época de semeadura. Em todos os tratamentos, o estádio R1 foi atingido quando as plantas estavam com o colar formado na sétima folha, ou seja, no estádio V7. A panícula diferenciada pode ser percebida a olho nu, através da realização de um corte longitudinal no colmo principal, observando a panícula recém iniciada na sua parte basal. Esta visualização não dá margens a erros, ao contrário do que acontece quando se usam termos como "green ring", muito utilizado em trabalhos (PAN et al., 1999) para referir-se ao estádio imediatamente anterior ao da diferenciação da panícula. O círculo verde escuro é perceptível através de um corte longitudinal do colmo, logo abaixo da inserção da última folha, imediatamente antes da iniciação da panícula.

O número de dias necessários para atingir o estádio de formação do colar na folha bandeira (R2) foi maior na cultivar BR-IRGA 409 (ciclo médio) e menor na cultivar IRGA 421 (ciclo superprecoce), nas três épocas de semeadura (Tabela 2). As três cultivares reduziram o número de dias necessários para atingir o estádio R2 com o atraso da semeadura. Esta redução se deve ao fato de que, com atraso da semeadura, a soma térmica necessária para atingir o estádio R2 é alcançada mais cedo. Este conceito de soma térmica é expresso como sendo a disponibilidade energética do meio, caracterizada pelo acúmulo diário de temperatura do ar. STEINMETZ et al. (2004), afirmam que existe uma relação inversa entre soma térmica e duração da fase vegetativa, havendo redução desta em anos mais quentes e alongamento em anos mais frios. INFELD et al. (1998) citam que a fase vegetativa da cultivar BRIRGA 410 variou de 42 a 75 dias, em doze anos de experimento de épocas de semeadura. Os mesmos autores também encontraram para o sub-período entre semeadura (S0) e diferenciação do primórdio da panícula (R1) valores de soma térmica de 536, 638 e 772 graus-dia, respectivamente, para cultivares de ciclo curto, médio e longo.

O número de folhas expandidas para atingir o estádio R2 foi similar para as cultivares de ciclo médio (BR-IRGA 409) e precoce (IRGA 417), mantendo-se em 14. A cultivar de ciclo superprecoce (IRGA 421) apresentou menor número de folhas expandidas ao 


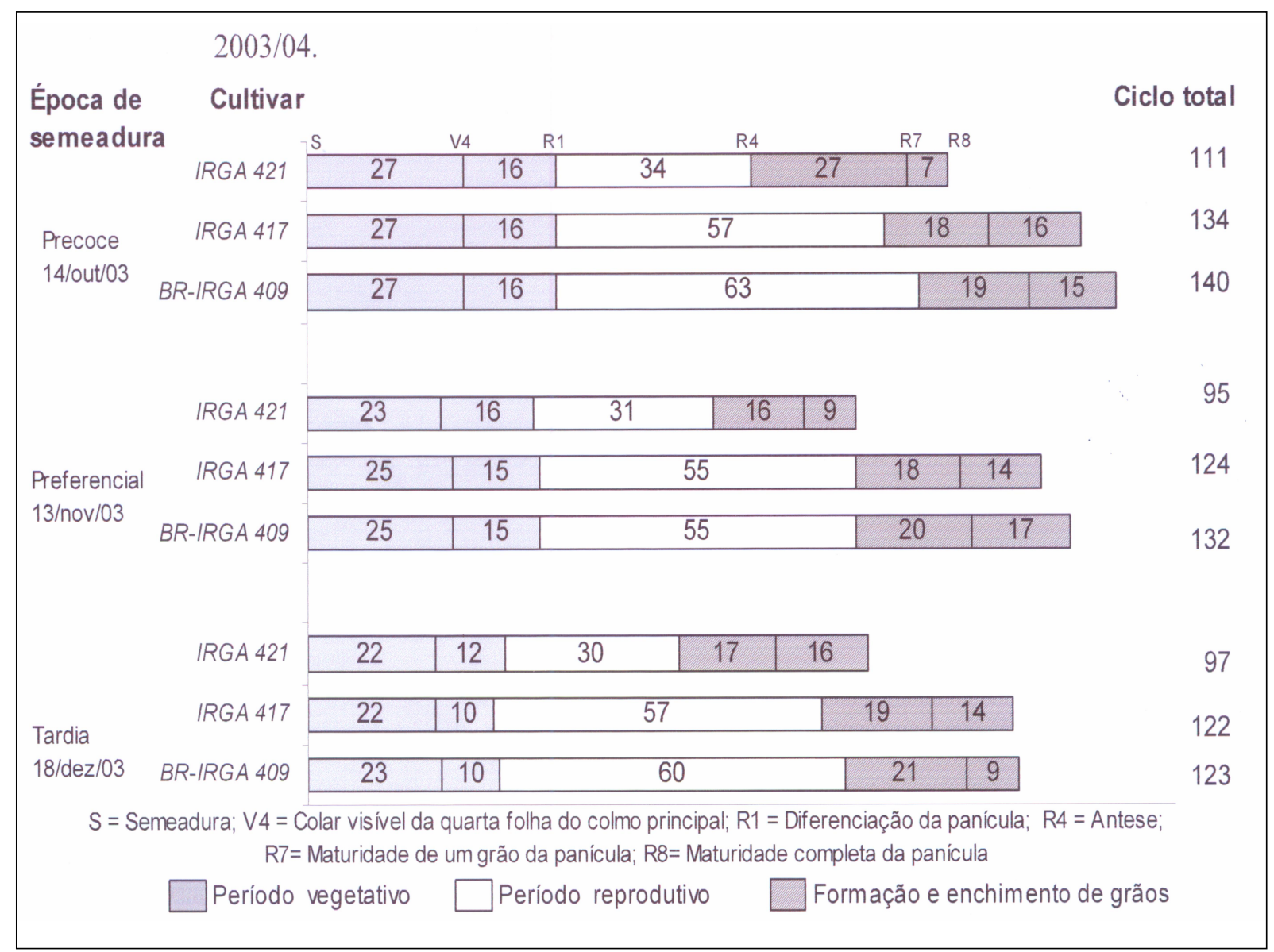

Figura 1 - Duração (dia) dos sub - períodos de desenvolvimento e do ciclo total de três cultivares de arroz irrigado, em três épocas de semeadura. Porto Alegre - RS

atingir este estádio nas três épocas de semeadura, reduzindo esta característica com atraso da época de semeadura. Na semeadura precoce, as plantas desta cultivar atingiram o estádio R2 com 12 folhas expandidas, enquanto nas semeaduras nas épocas preferencial e tardia este número diminuiu para 11 e 10, respectivamente.

Estes dados evidenciam que cultivares com ciclos contrastantes, semeadas em épocas distintas, apresentam maior variação no número de dias necessários após a emergência do que no número de folhas expandidas para atingir o mesmo estádio fisiológico. Outra constatação é que o uso da idade cronológica como critério para tomada de decisão da época de aplicação de práticas de manejo não é indicada, uma vez que existem variações expressivas entre época de semeadura, ciclo de cultivares, práticas de manejo e região de cultivo para atingir o mesmo estádio fisiológico.
As três cultivares de arroz irrigado testadas diferiram quanto à duração (dia) dos sub-períodos de desenvolvimento nas três épocas de semeadura. De um modo geral, à medida que a semeadura foi retardada, houve redução no ciclo total da cultura, e no número de dias necessários para atingir cada um dos estádios da escala proposta por COUNCE et al. (2000) (Figura 1). A redução na duração dos sub-períodos e do ciclo da cultura com o atraso na semeadura deve-se ao fato que ela responde à soma térmica, que é atingida mais rapidamente nas épocas de semeadura em que a temperatura do ar é mais elevada. A duração do subperíodo R1 a R2 foi que apresentou maior variação entre épocas de semeadura e cultivares. Desta forma, este sub-período pode ser considerado o mais variável durante o desenvolvimento da planta, por apresentar maior variação na resposta a estes dois fatores testados. Diferenças na duração do ciclo (dia) de desenvolvimento de duas cultivares de cafeeiro (Coffea 
Tabela 2 - Número de dias após emergência (DAE) e de folhas expandidas (NFE) para atingir os estádios de colar formado na $4^{\mathrm{a}}$ folha do colmo principal (V4) diferenciação da panícula (R1) e de formação do colar da folha bandeira (R2) em três cultivares de arroz irrigado, em três épocas de semeadura. Porto Alegre-RS, 2003/04.

\begin{tabular}{|c|c|c|c|c|c|c|}
\hline \multirow{3}{*}{ Época de semeadura } & \multirow{3}{*}{ Cultivar } & \multicolumn{5}{|c|}{ Estádio de desenvolvimento } \\
\hline & & \multirow{2}{*}{$\begin{array}{c}\mathrm{V} 4 \\
\mathrm{DAE}\end{array}$} & \multicolumn{2}{|c|}{$\mathrm{R} 1$} & \multicolumn{2}{|c|}{$\mathrm{R} 2$} \\
\hline & & & NFE & DAE & NFE & DAE \\
\hline Precoce & IRGA 421 & 18 & 7 & 34 & 12 & 58 \\
\hline \multirow[t]{2}{*}{ 14/out/03 } & IRGA 417 & 15 & 7 & 34 & 14 & 81 \\
\hline & BR-IRGA 409 & 18 & 7 & 34 & 14 & 88 \\
\hline Preferencial & IRGA 421 & 16 & 7 & 32 & 11 & 52 \\
\hline \multirow[t]{2}{*}{ 13/nov/03 } & IRGA 417 & 18 & 7 & 33 & 14 & 80 \\
\hline & BR-IRGA 409 & 18 & 7 & 33 & 14 & 81 \\
\hline Tardia & IRGA 421 & 15 & 7 & 27 & 10 & 46 \\
\hline \multirow[t]{2}{*}{ 18/dez/03 } & IRGA 417 & 15 & 7 & 25 & 14 & 70 \\
\hline & BR-IRGA 409 & 16 & 7 & 26 & 14 & 76 \\
\hline
\end{tabular}

arabica L.) também foram encontradas quando cultivadas em dois locais (PEZZOPANE et al., 2003). Segundo os autores, a partir do estádio "chumbinho" (início de formação de frutos, logo após a fecundação), as cultivares diferenciaram-se quanto ao ciclo fenológico, devido a diferenças na temperatura do ar e na disponibilidade hídrica durante as duas estações de crescimento.

\section{CONCLUSÕES}

A avaliação do desenvolvimento da planta através do uso do número de folhas com colar formado e de estádio de maturação dos grãos apresenta menor variação em função de época de semeadura e cultivar do que a expressão em números de dias após a emergência, sendo, portanto, de mais adequada utilização. A duração (dia) dos sub-períodos de desenvolvimento do arroz diminui com o atraso na semeadura, independente de ciclo de cultivar. A escala de desenvolvimento testada é de fácil uso e se adapta adequadamente para avaliar o desenvolvimento das plantas de cultivares brasileiras de arroz irrigado, independente de ciclo e época de semeadura. A diferenciação da panícula (R1) ocorre no estádio de sete folhas expandidas, independente de cultivar e época de semeadura adotadas.

\section{REFERÊNCIAS}

COSTA, J.A.; MARCHEZAN, E. Características dos estádios de desenvolvimento da soja. Campinas: Fundação Cargill, 1982. 30p.

COUNCE, P.A. et al. A uniform, objective, and adaptative system for expressing rice development. Crop Science, Madison, v.40, n.2, p.436-443, 2000.

CRUZ, R.P. Tolerância ao frio em arroz irrigado: metodologias de avaliação e bases genéticas. 2001. $158 f$. Tese (Doutorado em Fitotecnia) - Programa de Pós-graduação em Fitotecnia, Universidade Federal do Rio Grande do Sul.

FEHR, W.R.; CAVINESS, C.E. Stage of soybeans development. Ames: Iowa State University, 1977. 12p. (Special Report, 80).

INFELD, J.A.et al. Temperatura-base e graus-dia durante o período vegetativo de três grupos de cultivares de arroz irrigado. Revista Brasileira de Agrometeorologia, Santa Maria, v.6, n.2, p.187-191, 1998.

MARUR, C.J.; RUANO, O. Escala do algodão: um método para determinação de estádios de desenvolvimento do algodoeiro herbáceo. Piracicaba: POTAFOS, 2004. p.3-4. (Informações Agronômicas, n.105).

MUNDSTOCK, C.M. Planejamento e manejo integrado da lavoura de trigo. Porto Alegre: o autor, 1999. 228p. 
PAN, X.B. et al. Major gene, nonallelic sheath blight resistence from the rice cultivars Jasmine 85 and Teqing. Crop Science, Madison, v.39, n.2, p.338-346,1999.

PEZZOPANE, J.R.M. et al. Escala para avaliação de estádios fenológicos do cafeeiro arábica. Bragantia, Campinas, v. 62, n.3, p.499-505, 2003.

RITCHIE, S.W. et al. How a corn plant develops. Ames: Iowa State University of Science and Technology, Cooperative Extension Service, 1993. 21p. (Special Report, 48). Acesso em: 15 jun 2005. Online. Disponível em: www.maize.agron.iastate.edu/corngrows.html.

SOCIEDADE SUL-BRASILEIRA DE ARROZ IRRIGADO (SOSBAI). Arroz Irrigado: recomendações técnicas da pesquisa para o Sul do Brasil. Itajaí, SC: SOSBAI, 2003. 126p.

STEINMENTZ, S. et al. Uso do método de graus-dia para estimar a data de diferenciação da panícula de grupos de cultivares de arroz irrigado no Rio Grande do Sul. Pelotas: Embrapa Clima Temperado, 2004. 36p. Documentos, 126. 